\title{
Effect of blood type on anti- $\alpha$-Gal immunity and the incidence of infectious diseases
}

\author{
Alejandro Cabezas-Cruz ${ }^{1,7}$, Lourdes Mateos-Hernández ${ }^{2}$, Pilar Alberdi², Margarita Villar ${ }^{2}$, Gilles Riveau ${ }^{1,3}$, \\ Emmanuel Hermann ${ }^{1,3}$, Anne-Marie Schacht ${ }^{1,3}$, Jamal Khalife ${ }^{1}$, Margarida Correia-Neves ${ }^{4,5}$, Christian Gortazar ${ }^{2}$ \\ and José de la Fuente ${ }^{2,6}$
}

The identification of factors affecting the susceptibility to infectious diseases is essential toward reducing their burden on the human population. The ABO blood type correlates with susceptibility to malaria and other infectious diseases. Due to the structural similarity between blood antigen B and Gal $\alpha 1-3 G$ al $\beta 1-(3) 4 G I c N A c-R$ ( $\alpha$-Gal), we hypothesized that self-tolerance to antigen $B$ affects the immune response to $\alpha$-Gal, which in turn affects the susceptibility to infectious diseases caused by pathogens carrying $\alpha$-Gal on their surface. Here we found that the incidence of malaria and tuberculosis, caused by pathogens with $\alpha$-Gal on their surface, positively correlates with the frequency of blood type B in endemic regions. However, the incidence of dengue fever, caused by a pathogen without $\alpha$-Gal, was not related to the frequency of blood type B in these populations. Furthermore, the incidence of malaria and tuberculosis was negatively correlated with the anti- $\alpha$-Gal antibody protective response. These results have implications for disease control and prevention.

Experimental \& Molecular Medicine (2017) 49, e301; doi:10.1038/emm.2016.164; published online 10 March 2017

\section{INTRODUCTION}

The $\mathrm{ABO}$ histo-blood groups consist of two antigens (A and $\mathrm{B}$ ), and four blood types (A, B, AB and $\mathrm{O}$ ), of which blood types $\mathrm{A}, \mathrm{B}$ and $\mathrm{O}$ are the most frequent among human populations, with the $\mathrm{O}$ type being the most common. ${ }^{1}$ The blood type $\mathrm{O}$ results from the homozygous inheritance of two null $\mathrm{ABO}$ alleles and individuals in this group express the antigen $\mathrm{H}$, the precursor of blood types $A$ and $B^{1}$. The $A B H$ antigens are carbohydrates attached to glycosphingolipids and glycoproteins. In general, humans have antibodies against missing A or B antigens. ${ }^{1}$ Therefore, individuals with blood type A have antibodies against antigen $B$, but not against selfantigen $\mathrm{A}^{2}$. Individuals with blood type $\mathrm{O}$ have antibodies against both $\mathrm{A}$ and $\mathrm{B}$ antigens. ${ }^{2}$ The origin of anti-antigen A antibodies is still controversial, but anti-antigen B antibodies are associated with immunity to gut microbiota. ${ }^{3,4}$ The composition of blood groups is frequently used in epidemiological studies because they constitute genetically determined traits with polymorphic expression at the individual and population levels. ${ }^{1}$ Blood-type differences have been associated with susceptibility to and severity of malaria and other diseases. ${ }^{1,5,6}$ For example, blood type $\mathrm{O}$ protects against malaria through reduced rosetting. ${ }^{7}$ In contrast, individuals with blood type A are more susceptible to severe malaria. ${ }^{8}$ Therefore, malaria has been recognized as a major evolutionary pressure on blood type at the population level. ${ }^{1,5,7,8}$

The structure of antigen B (Gal $\alpha 1-3($ Fucol,2)Gal) is very similar to Gal $\alpha 1-3 \mathrm{Gal} \beta 1-(3) 4 \mathrm{GlcNAc}-\mathrm{R}$ ( $\alpha$-Gal). During evolution, humans lost the gene encoding the enzyme to synthesize the carbohydrate $\alpha$-Gal that resulted in an almost unique capacity to produce high antibody titers against $\alpha$-Gal. ${ }^{9}$ These antibodies appear early in life ${ }^{10}$ and are continuously produced in response to gut microbiota. ${ }^{3,11}$ However, individuals with antigen $\mathrm{B}$ have a reduced antibody response against the related antigens $\alpha$-Gal and Gal $\alpha 1-3 \mathrm{Gal} .{ }^{12,13}$ It was recently demonstrated that anti- $\alpha-$ Gal antibodies inhibit Plasmodium spp.

\footnotetext{
${ }^{1}$ Center for Infection and Immunity of Lille (CIIL), Université Lille Nord de France, Institut Pasteur de Lille, Lille, France; ²SaBio, Instituto de Investigación en Recursos Cinegéticos IREC-CSIC-UCLM-JCCM, Ronda de Toledo s/n, Ciudad Real, Spain; ${ }^{3}$ Centre de Recherches Biomédicales Espoir pour la Sante, SaintLouis, Senegal; ${ }^{4}$ Life and Health Sciences Research Institute (ICVS), School of Health Sciences, University of Minho, Braga, Portugal; ${ }^{5}$ ICVS/3B's, PT Government Associate Laboratory, Braga/Guimarães, Portugal and ${ }^{6}$ Department of Veterinary Pathobiology, Center for Veterinary Health Sciences, Oklahoma State University, Stillwater, OK, USA

${ }^{7}$ Current address: Institute of Parasitology, Biology Center of the Academy of Sciences of the Czech Republic, and Faculty of Science, University of South Bohemia, 37005 České Budějovice, Czech Republic.

Correspondence: Professor J de la Fuente, SaBio, Instituto de Investigación en Recursos Cinegéticos IREC-CSIC-UCLM-JCCM, Ronda de Toledo s/n, Ciudad Real 13005, Spain.

E-mail: jose_delafuente@yahoo.com

Received 21 September 2016; revised 3 November 2016; accepted 7 November 2016
} 
transmission by Anopheles spp. mosquitoes, with a positive correlation between the levels of anti- $\alpha-G a l$ IgM antibodies and the incidence of $P$. falciparum infection. ${ }^{14}$ This finding suggests that anti- $\alpha-G a l$ IgM antibodies might protect against infection by Plasmodium spp. parasites and other pathogens containing $\alpha$-Gal on their surface. ${ }^{15,16}$ In contrast, anti- $\alpha$-Gal IgE antibodies may correlate with food allergies. ${ }^{17-19}$

These findings suggested the hypothesis that self-tolerance to blood antigen B may affect the immune response to $\alpha-\mathrm{Gal}$, with a major impact on the susceptibility to certain infectious diseases and food allergies. If true, the incidence of infectious diseases caused by pathogens with $\alpha$-Gal on their surface (for example, malaria and tuberculosis) should positively correlate with the frequency of blood type $B$, while the prevalence of diseases caused by pathogens without $\alpha-\mathrm{Gal}$ moieties (for example, dengue fever) and allergies related to anti- $\alpha$-Gal IgE antibodies (for example, allergy to red meat) should not be correlated or should be negatively correlated with the frequency of blood type B.

\section{MATERIALS AND METHODS}

\section{$\mathrm{ABO}$ blood group frequency data collection and processing} The ABO blood group frequency data were collected from 132 manuscripts. The following criteria were applied to remove unreliable or unnecessary information and to obtain reliable national estimates of $\mathrm{ABO}$ blood group frequencies: (i) all studies that were focused on disease group populations were excluded from the analysis as they could bias the analysis. However, in studies that included control (healthy) and target (disease) groups, the two sets of frequencies were pooled and reported as a single value for that country; (ii) for the same reason, all studies that focused on particular ethnic groups were excluded. However, in studies where representative ethnic groups from a country were included, the whole set of frequencies of each blood group was pooled and reported as a single value for that country; (iii) all studies that did not include all the $\mathrm{ABO}$ blood types ( $A, B, O$ and $A B$ ) were excluded from the analysis; (iv) the studies in which $<50$ individuals were analyzed were excluded. Only one study was included with $<100$ individuals; (v) in addition, a rule was applied to obtain more representative and accurate national $\mathrm{ABO}$ blood type frequency reports. When more than one report per country was found in the literature, an average $\mathrm{ABO}$ blood type frequency from these studies was calculated and used as the country ABO blood type frequency report.

The ABO blood group frequency data collection resulted in a database obtained from 105 references for 82 countries from Africa $(N=26 ; 488045$ individuals), Asia $(N=21 ;>4709411$ individuals), America ( $N=15 ;>3592783$ individuals), Europe $(N=18$; > 1029338 individuals $)$ and Oceania $(N=2 ;>2802$ individuals). Data on $\mathrm{ABO}$ blood type frequency per country and a complete list of references are available in Supplementary Table 1.

\section{Disease data collection and processing}

Data were collected for malaria and tuberculosis, caused by pathogens containing $\alpha-\mathrm{Gal}$ on their surface, and for dengue fever as a control disease caused by a virus without $\alpha$-Gal on its surface. The list of malaria endemic countries was collected from Oxford's Malaria Atlas Project (MAP) website (http://www.map.ox.ac.uk). ${ }^{20}$ The list includes 100 countries from Africa, America and Asia. We attempted to include most countries in the analysis. Particularly in Africa, MAP includes 44 malaria endemic countries for which incidence data were reported from 2000 to 2015 (Supplementary Table 2). ${ }^{21}$ Incidence data for Sudan were not available at MAP, and blood type frequency data were not available for the 44 malaria endemic countries. Therefore, our final data set for malaria in Africa was composed of 25 countries (Supplementary Table 2). The number of deaths due to malaria in Africa, Asia and America was collected from the World Malaria Report 2015 (Supplementary Table 3). ${ }^{22}$ Cumulative incidence per country was calculated as the sum of all malaria incidences per year using MAP data. The percentage reduction in malaria incidence was calculated as the percent of cases that resulted from the comparison of the incidence in 2000 vs 2015 using MAP data.

Data on the incidence of tuberculosis and dengue fever were collected from Quandl ${ }^{23}$ and Bhatt et al. ${ }^{24}$ respectively. Bhatt et al. ${ }^{24}$ reported the apparent and unapparent mean dengue fever burden estimates per country. For correlation analysis, we used the apparent mean per country. Incidence data per country were then divided as per the population of the country and multiplied by 100. Final incidence values (expressed as a percentage) for tuberculosis and dengue fever are available in Supplementary Table 4.

\section{Statistical analysis of the correlation between blood type frequency and disease incidence/prevalence}

Statistical correlation was evaluated using the non-parametric Spearman test. One-way analysis of variance was used to test the statistical significance of the distribution of $\mathrm{ABO}$ blood type frequencies per region. All statistical analyses were performed using the GraphPad 6 Prism program (GraphPad Prism v6, GraphPad Software Inc., La Jolla, CA, USA). Differences were considered significant when $P$-value $<0.05$ using the one-tail test.

\section{Ethics statement}

Serum samples from malaria patients were obtained under a protocol approved by the National Ethics Committee of the Ministry of Health of Senegal (October 2008; 0084/MSP/DS/CNRS, ClinicalTrials.gov ID: NCT01545115). Serum samples from tuberculosis patients were collected in the context of a previous study and approved by the Ethics Board of the Hospital de S. João, Porto, Portugal. ${ }^{25}$ Oral and written informed consents were obtained from the adult individuals, or from the parents or legal guardians of the children.

\section{Serum samples}

Serum samples from malaria patients during the chronic disease phase and uninfected healthy individuals were obtained from children in Northern Senegal (Podor District) as previously reported. ${ }^{26}$ The area is located in a dry savannah with a dry season from November to June and a short rainy season from July to October. ${ }^{26,27}$ In this region, malaria due to P. falciparum shows a low and seasonal incidence, where peaks of infections appear after the rainy season. ${ }^{28}$ Anopheles gambiae s.l. is the major malaria vector in the Podor District. ${ }^{26,28}$ Samples were collected from the Niandane village in the month of January 2009, after the rainy season when a peak of malaria transmission by An. gambiae s.l. was recorded. ${ }^{26}$ Samples from infected $(N=22)$ and uninfected $(N=26)$ children were included in the study (Supplementary Table 5). Serum samples from patients with untreated pulmonary tuberculosis or during the first week of treatment $(N=41)$ and uninfected healthy individuals $(N=43)$ were obtained from adults in the Iberian Peninsula (Portugal and Spain) (Supplementary Table 6). 


\section{Determination of anti- $\alpha$-Gal IgG, IgM and IgE antibody} titers

Anti- $\alpha$-Gal IgG, IgM and IgE antibody titers were determined in serum samples from malaria and tuberculosis patients and uninfected individuals. ELISA plates were coated with $100 \mu \mathrm{l}$ per well $(100 \mathrm{ng})$ of

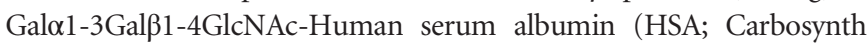
Ltd, Berkshire, UK) in carbonate/bicarbonate buffer and incubated overnight at $4{ }^{\circ} \mathrm{C}$. Then, $100 \mu \mathrm{l}$ of blocking buffer (1\% HSA in phosphate-buffered saline, PBS supplemented with $0.05 \%$ Tween 20 , PBST; Sigma-Aldrich, Madrid, Spain) was added to each well and incubated for $1 \mathrm{~h}$ at room temperature (RT) followed by five washes with PBST. The sera were added to plates at 1:50 dilution in blocking buffer and incubated for $1 \mathrm{~h}$ at $37^{\circ} \mathrm{C}$, followed by five washes with PBST. Goat anti-human immunoglobulins-peroxidase $\operatorname{IgG}$ (FC specific), IgM ( $\mu$-chain specific) or IgE ( $\varepsilon$-chain specific; SigmaAldrich) were added at 1:1000 dilution in blocking buffer $(100 \mu \mathrm{l}$ per well), and plates incubated for $1 \mathrm{~h}$ at RT. Plates were then washed five times with PBST, and color was developed by the addition of $100 \mu \mathrm{l}$ of 3,3',5,5'-tetramethylbenzidine (Promega Biotech, Madrid, Spain) and protected from the light for $20 \mathrm{~min}$ at RT. Reactions were stopped with the addition of $50 \mu \mathrm{l}$ sulfuric acid, and the optical densities (OD) were measured at $450 \mathrm{~nm}$ with an ELISA reader. The average value of the blanks (wells without Gala1-3Galb1-4GicNAc-HSA coating; $N=4$ ) was subtracted from all reads, and the average of two replicates for each sample was used for analysis (Supplementary Tables 5 and 6).

A standard curve was constructed with sera from selected patients and controls for anti- $\alpha$-Gal IgE antibody levels determined by ELISA and using the ImmunoCAP Phadia 250 automated platform (Thermo Fisher Scientific, Uppsala, Sweden) with the commercial ImmunoCap $\alpha$-Gal bovine Thyroglobulin kit according to the manufacturer instructions. This experiment provided support for the binding of anti- $\alpha$-Gal IgE antibodies to $\alpha$-Gal and allowed us to set the ELISA cutoff for anti- $\alpha$-Gal IgE positivity at $\mathrm{OD}_{450 \mathrm{~nm}}$ of 0.3 .

\section{Statistical analysis of the anti- $\alpha-G a l$ antibody titers between infected and uninfected individuals}

Outliers in values for antibody titers were identified using the ROUT method implemented in GraphPad 6 Prism program (GraphPad Prism v6, GraphPad Software Inc.). Identified outliers corresponded to malaria IgM (samples ID 8, 9, 11, 29, 44 and 46), IgG (samples ID $24,30,31,44$ and 46), and tuberculosis IgM (samples ID 23, 41, 27c and $40 \mathrm{c}$ ). Outliers were removed from the final data sets for analysis using the nonparametric Mann-Whitney $U$-test to compare values between infected and uninfected groups $(P=0.05)$.

\section{Bacterial strains and growth conditions}

Mycobacterium marinum CECT 7091 reference strain (Colección Española de Cultivos Tipo, Valencia, Spain) was grown in sterile $250 \mathrm{ml}$ flasks with 7H9 liquid medium supplemented with ADC (Becton Dickinson, Franklin Lakes, NJ, USA) and incubated at $31^{\circ} \mathrm{C}$ with continuous shaking for 7 days in the dark. Spectrophotometric absorbance was measured at $600 \mathrm{~nm}\left(\mathrm{OD}_{600}\right)$ and the concentration was adjusted to $10^{8}-10^{9} \mathrm{CFU} \mathrm{ml}^{-1}$. The Escherichia coli O86:B7 (ATCC 12701) and BL21 (DE3; Invitrogen, Carlsbad, CA, USA) strains were included as positive and negative controls for $\alpha$-Gal, respectively, ${ }^{14}$ inoculated into $50 \mathrm{ml}$ of Luria Broth (LB), and incubated at $37^{\circ} \mathrm{C}$ overnight.

\section{Detection of $\alpha-G a l$ in bacterial cultures}

The E. coli O86:B7, E. coli BL21 (DE3) and M. marinum cell cultures were washed $2 \times$ in PBS $(4000 g, 5 \mathrm{~min})$ and re-suspended in PBS. Bacteria were fixed in $200 \mu \mathrm{l} 4 \%$ paraformaldehyde in PBS for $30 \mathrm{~min}$ at RT and washed once in PBS. To visualize $\alpha$-Gal, $10^{8}-10^{9} \mathrm{CFU} \mathrm{ml}{ }^{-1}$ were stained with $200 \mu \mathrm{l}$ of BS-I Isolectin B4 (BSI-IB 4 -FITC), which is a lectin-specific for $\alpha$-Gal from Bandeiraea simplicifolia ${ }^{14}\left(50 \mu \mathrm{g} \mathrm{ml}{ }^{-1}\right)$ (Sigma-Aldrich; http://www.sigmaaldrich.com/content/dam/sigmaaldrich/docs/Sigma/Product_Information_Sheet/2/12895pis.pdf), for $2 \mathrm{~h}$ at RT and then analyzed by flow cytometry using a FACScalibur Flow Cytometer, equipped with the CellQuest Pro software (BD Biosciences, Loveton Circle, MD, USA). The viable cell population was gated according to forward scatter and side scatter parameters. Ten microliters of the fixed and stained samples were also used for immunofluorescence assays after air-drying and mounting in ProLong Antifade reagent containing DAPI (Molecular Probes, Eugene, OR, USA). Images were acquired on a Nikon Eclipse Ti-U microscope with a $\times 60$ objective and a Nikon Digital Sight DS Vil camera.

\section{RESULTS}

Malaria incidence positively correlates with the frequency of blood type $B$

To address this hypothesis, we collected data on the incidence of malaria, a disease affecting 200 million people yearly and caused by Plasmodium spp. parasites, ${ }^{29}$ and the frequency of blood types A, B, O and $\mathrm{AB}$ in countries from Africa, Asia, Europe and America to perform correlation analyses (Supplementary Table 1). Blood-type B is present in $<20 \%$ of the population in all countries from America and Europe, while this blood type is highly prevalent in malaria endemic countries from Africa and Asia (Figure 1a and Supplementary Figure 1). The frequency of blood-type $B$ was negatively correlated with the frequency of blood-type A in Africa, Asia and Europe, but not in America (Supplementary Figure 2). Using the malaria incidence spanning from 2000 to 2015 (Supplementary Table 2), we observed that African countries with the highest incidence of malaria have the minimum and maximum frequencies of blood types $\mathrm{A}$ and $\mathrm{B}$, respectively (Figures $1 \mathrm{~b}$ and $2 \mathrm{a}$ ). The number of deaths due to malaria in Africa in 2014 (Supplementary Table 3) was also positively correlated with the frequency of blood-type B, but not the frequency of blood type A (Figure 2b). Malaria incidence decreased in Africa from 2000 to $2015,{ }^{21}$ a result that correlated with a reduction in the frequency of blood type B (Figure 2c). However, no correlation was found between the frequencies of blood types $\mathrm{O}$ or $\mathrm{AB}$ and malaria incidence (Supplementary Figure 3).

These results demonstrated that malaria incidence positively correlates with the frequency of blood type B.

\section{Tuberculosis, but not dengue fever, incidences positively} correlate with the frequency of blood type B

To test the hypothesis for other infectious diseases, tuberculosis and dengue fever were selected based on their incidence ${ }^{30,31}$ and different causative agents (intracellular bacteria of the Mycobacterium tuberculosis complex and dengue virus 

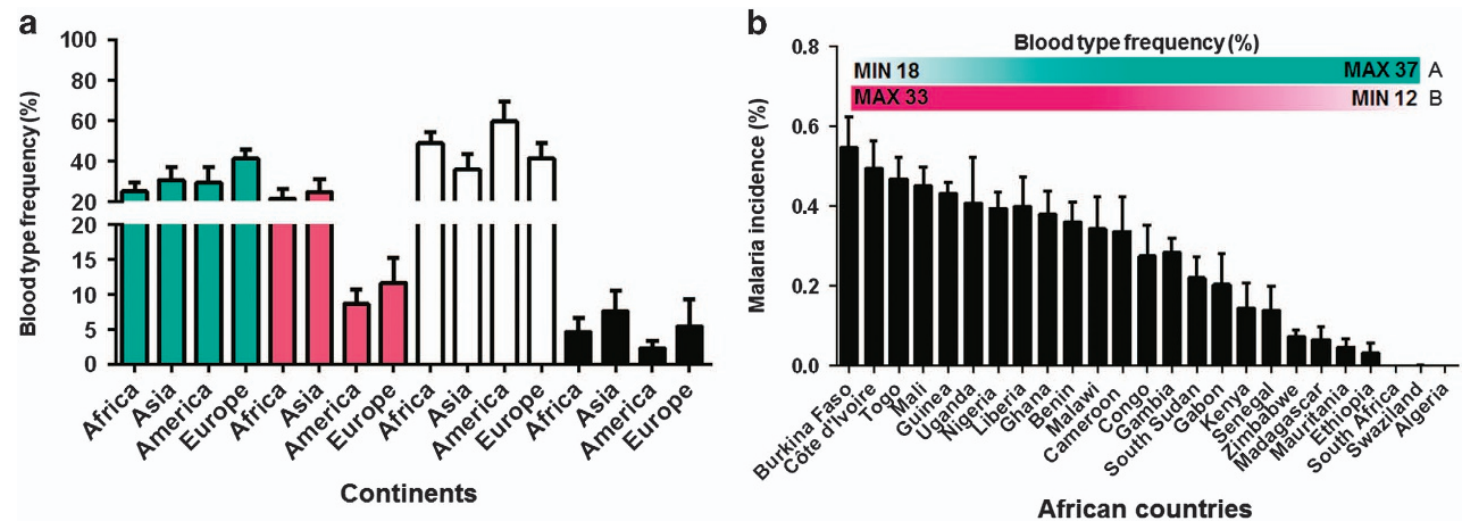

Figure 1 ABO blood types and malaria incidence. (a) Frequency of ABO blood types in Africa, Asia, America and Europe. Information on the distribution of blood types A (cyan), B (magenta), $O$ (white) and AB (black) in 82 countries was collected from the literature (Supplementary Table 1). Significant differences were observed between continents for the same blood type (one-way ANOVA test; $P<0.0001$ ) and between blood types within the same continent (one-way ANOVA test; $P<0.0001$ ). (b) Cumulative (2000-2015) malaria incidence in African countries was compared with blood type frequency. A negative correlation was observed between the frequency of blood-type A (Supplementary Table 1) and malaria incidence (Spearman $r=-0.52, P=0.003$ ), while the correlation was positive between the frequency of blood-type $B$ and malaria incidence (Spearman $r=0.58, P=0.001$ ). No significant correlation was found between the frequency of blood types $O$ (Spearman $r=0.05, P=0.39$ ) or $A B$ (Spearman $r=0.07, P=0.35$ ) and malaria incidence. The countries with the highest malaria incidence have the lowest and highest values for the frequencies of blood types $\mathrm{A}$ (minimum value, MIN $18 \%$ ) and $\mathrm{B}$ (maximum value, MAX 33\%) in the population, respectively. The countries with the lowest malaria incidence have the highest and lowest values for the frequencies of blood types $A(M A X 37 \%)$ and B (MIN 12\%) in the population, respectively.

a
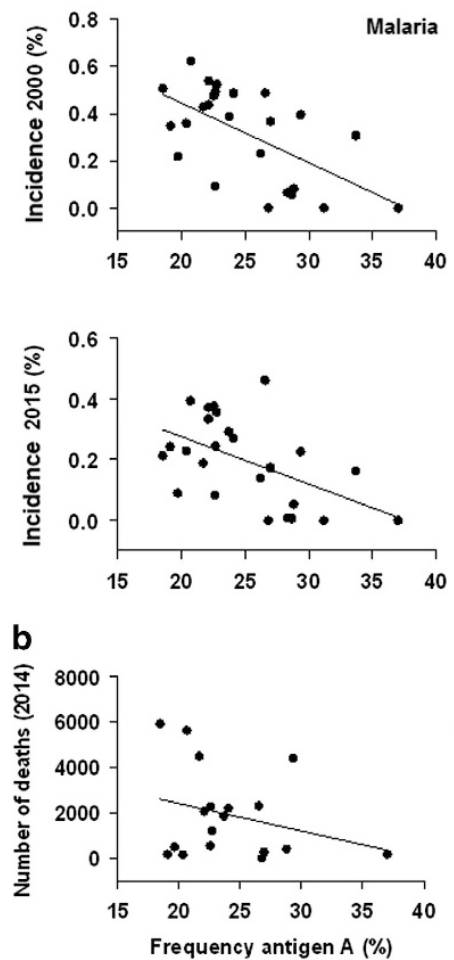
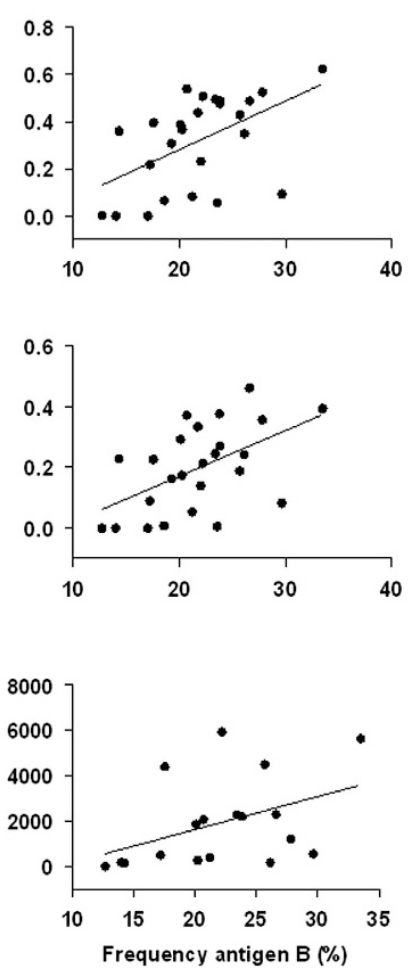
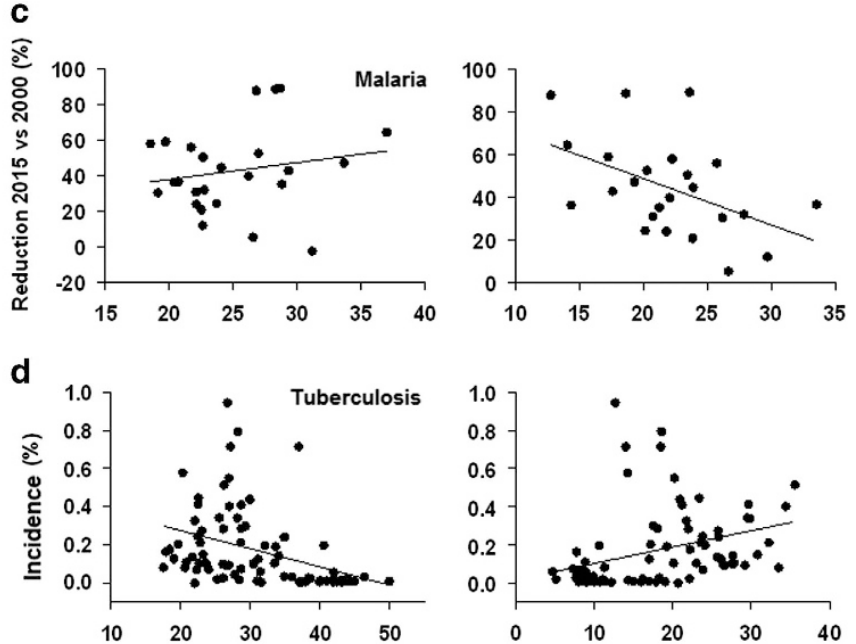

e

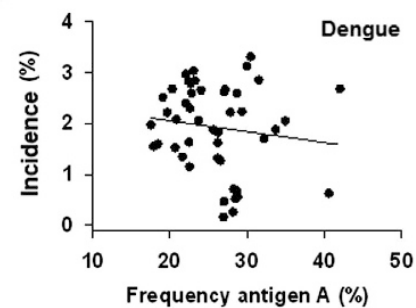

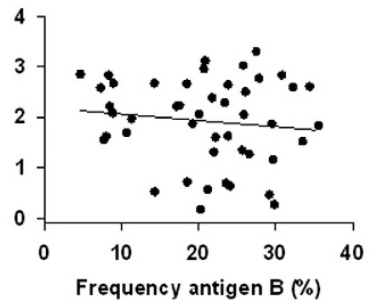

Figure 2 Correlation between $\mathrm{ABO}$ blood types and disease. (a) Correlation analysis between the frequencies of blood types $\mathrm{A}$ and $\mathrm{B}$ (Supplementary Table 1) and malaria incidence in Africa in 2000 and 2015 (Supplementary Table 2). Spearman's rank correlation coefficient tests were significant for blood types A (Spearman $r \leqslant-0.50, P \leqslant 0.004$ ) and B (Spearman $r \geqslant 0.55, P \leqslant 0.002$ ) in both years 2000 and 2015. (b) Correlation between the number of deaths due to malaria in 2014 and the frequencies of blood types $A$ (Spearman $r=-0.19, P=0.21$ ) and $B$ (Spearman $r=0.50, P=0.01$ ) in Africa. (c) Correlation between the percentage of reduction in malaria

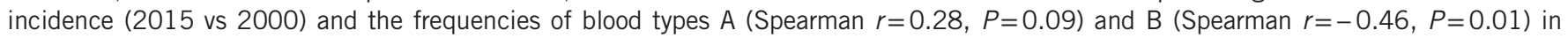
Africa. (d) Correlation between the frequencies of blood types A (Spearman $r=-0.54, P<0.0001$ ) and B (Spearman $r=0.51, P<0.0001$ ) and the incidence of tuberculosis in Africa, Asia, America and Europe. (e) Correlation between the frequencies of blood types A and B and the incidence of dengue fever in Africa, Asia, America and Europe. 
a

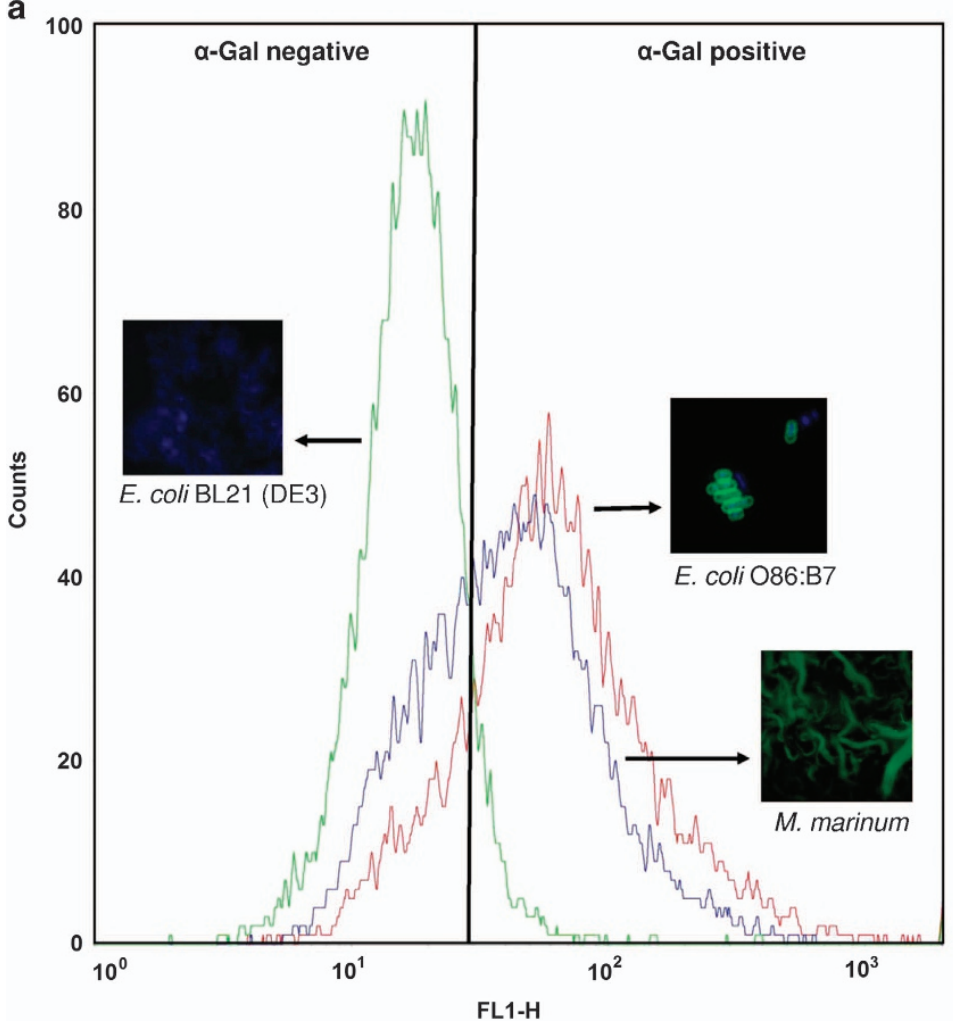

b
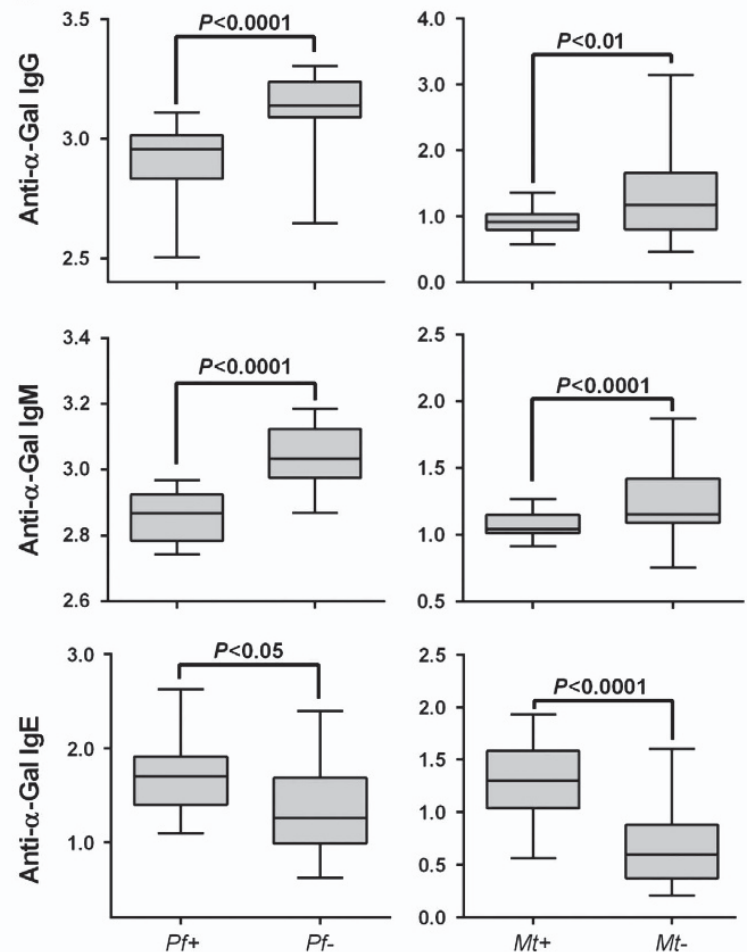
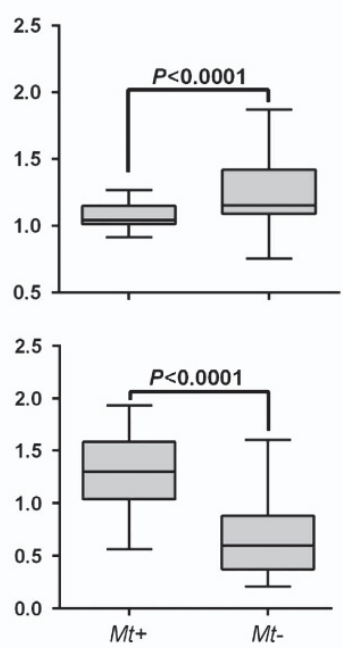

Figure 3 Correlation between anti- $\alpha$-Gal antibodies and protection against malaria and tuberculosis. (a) Flow cytometry and immunofluorescence showing the presence of $\alpha$-Gal on the surface of mycobacteria (Mycobacterium marinum CECT 7091 reference strain). Escherichia coli 086:B7 (ATCC 12701) and BL21 (DE3) strains were included as positive and negative controls for $\alpha$-Gal, respectively. For flow cytometry, cells were stained with BSI-IB 4 -FITC to visualize $\alpha$-Gal and the viable cell population was gated according to forward scatter and side scatter parameters. Ten microliters of the fixed and stained samples were also used for immunofluorescence assays after air-drying and mounted in ProLong Antifade reagent containing DAPI. Representative immunofluorescence images are shown for bacterial cells stained with BSI-IB 4 -FITC (anti- $\alpha$-Gal-FITC, green; blue, DAPI). (b) Anti- $\alpha$-Gal antibody titers in patients with malaria or tuberculosis and healthy individuals. The levels of anti- $\alpha-G a l$ IgM and IgG antibodies were significantly higher in $P$. falciparum uninfected (Pf-) vs infected $\left(P f_{+}\right)$individuals from Senegal. A similar pattern was observed in $M$. tuberculosis uninfected $(M t-)$ vs infected $(M t+)$ individuals from the Iberian Peninsula. The levels of anti- $\alpha-G a l$ IgE antibodies were lower in both $M t+$ and Pf+ patients, when compared with $M t-$ and $P f-$ healthy individuals, respectively. The nonparametric Mann-Whitney $U$-test was used to compare values between infected and uninfected groups $(P=0.05)$.

transmitted by Aedes spp. mosquitoes, respectively). Data were collected from countries in Africa, Asia, America and Europe (Supplementary Table 4). As shown for malaria, a positive and negative correlation was observed between tuberculosis incidence and the frequencies of blood types $\mathrm{B}$ and $\mathrm{A}$, respectively (Figure 2d and Supplementary Figure 4A). However, no correlation was found between blood type and dengue fever incidence (Figure $2 \mathrm{e}$ and Supplementary Figure 4B).

The incidence of malaria and tuberculosis, caused by pathogens with $\alpha$-Gal on their surface, negatively correlates with the anti- $\alpha-G a l$ antibody protective response

The presence of $\alpha$-Gal on the surface of Plasmodium spp. parasites have been demonstrated and relate to the effect of anti- $\alpha$-Gal antibodies on $P$. falciparum infection. ${ }^{14}$ The $\alpha$-Gal epitope has also been found on the surface of Leishmania spp. and Trypanosoma spp. parasites, ${ }^{16}$ bacteria of the gut microbiota, ${ }^{32}$ and other pathogenic bacteria such as mycobacteria (Figure 3a), but not in viruses. Furthermore, preliminary experimental evidence with $P$. falciparum-infected and uninfected individuals from Senegal, and M. tuberculosisinfected and -uninfected individuals from the Iberian Peninsula showed that the levels of anti- $\alpha-G a l$ IgM and IgG, but not IgE antibodies, were significantly higher in uninfected than infected individuals (Figure 3b; Supplementary Tables 5 and 6), providing support for the negative correlation between the incidence of these infectious diseases and the anti- $\alpha-G a l$ IgM and IgG antibody protective response.

\section{DISCUSSION}

According to our hypothesis, the high frequency of blood antigen B is associated with reduced immune response to $\alpha$ Gal, thus resulting in higher susceptibility to infectious diseases caused by pathogens with $\alpha$-Gal on their surface and a lower prevalence of food allergies such as red meat allergy that are related to anti- $\alpha$-Gal IgE antibodies. 
Galili et al. ${ }^{33}$ suggested that individuals with blood types B or $\mathrm{AB}$ would be tolerogenic to the fucosylated $\alpha$-Gal epitope present in antigen $B$. Nevertheless, all healthy individuals are able to produce antibodies against $\alpha$-Gal regardless of the blood type. ${ }^{33-35}$ However, recent results have shown that the levels of anti- $\alpha-$ Gal antibodies are lower in individuals with blood antigen B. ${ }^{12,36,37}$ Furthermore, the anaphylaxis to red meat consumption is associated to the presence of anti- $\alpha-\mathrm{Gal}$ IgE antibodies in affected patients ${ }^{17-19}$ with low antigen $B$ frequency. $^{12}$

Together, these results support our hypothesis that the presence of the blood antigen B correlates with increased susceptibility to malaria and other infectious diseases caused by pathogens carrying $\alpha$-Gal on their surface. The antigenic similarity $^{12}$ and possible cross-reactivity between the antigen $B$ and $\alpha$-Gal probably limits the production of anti- $\alpha$-Gal antibodies due to self-tolerance to antigen $\mathrm{B}^{2}$. This tolerance may affect the production of anti- $\alpha$-Gal antibodies generated in response to gut microbiota and arthropod vector saliva-derived proteins. ${ }^{14,15}$ The presence of the blood antigen A may favor the production of not only anti- $\alpha$-Gal but also anti-antigen $\mathrm{B}$ antibodies, which may cross-react with $\alpha$-Gal epitopes on the surface of Plasmodium spp. and other pathogens. In fact, anti-B antigen antibodies in individuals with blood types $\mathrm{A}$ and $\mathrm{O}$ are primarily due to anti- $\alpha$-Gal antibodies capable of recognizing both $\alpha-G a l$ and antigen B epitopes. ${ }^{12}$

These results have important implications for the control and treatment of infectious diseases. The higher anti- $\alpha-\mathrm{Gal}$ antibody response in individuals with blood type A may facilitate and increase the immunity against pathogen infection resulting in enhanced protection against disease. Retargeting pre-existing anti- $\alpha$-Gal antibodies to pathogens with an alphaGal-conjugated aptamer could be developed as a novel therapeutic approach. ${ }^{38}$ In addition, the recent finding that increased abundance of $\alpha$-Gal producing bacteria, Lactobacillus and Bifidobacterium in the gut microbiota affects Plasmodium infection in mice. ${ }^{39}$ This opens the possibility of using probiotics as potential interventions to reduce disease severity, which may also be conditioned by blood type in humans. ${ }^{40}$

\section{CONFLICT OF INTEREST}

The authors declare no conflict of interest.

\section{ACKNOWLEDGEMENTS}

The research was partially supported by the European Union projects, ANTIcipating the Global Onset of Novel Epidemics (ANTIGONE) project number 278976, and the COllaborative Management Platform for detection and Analyses of (Re-) emerging and foodborne outbreaks in Europe (COMPARE) Grant 643476. We thank Vladimir López (IREC, Spain) for the contribution of M. marinum samples and José Alberto García Seco (Hospital General Universitario de Ciudad Real, Spain) for technical assistance.

1 Cooling L. Blood groups in infection and host susceptibility. Clin Microbiol Rev 2015; 28: 801-870.
2 Rieben R, Tucci A, Nydegger UE, Zubler RH. Self tolerance to human A and $B$ histo-blood group antigens exists at the $B$ cell level and cannot be broken by potent polyclonal B cell activation in vitro. Eur J Immunol 1992; 22: 2713-2717.

3 Galili U, Mandrell RE, Hamadeh RM, Shohet SB, Griffiss JM. Interaction between human natural anti-alpha-galactosyl immunoglobulin $G$ and bacteria of the human flora. Infect Immun 1988; 56: 1730-1737.

4 Branch DR. Anti-A and anti-B: what are they and where do they come from? Transfusion 2015; 55: S74-S79.

5 Williams TN. Red blood cell variants and malaria: a long story not yet over. Lancet Haematol 2015; 2: e130-e131.

6 Liumbruno GM, Franchini M. Beyond immunohaematology: the role of the ABO blood group in human diseases. Blood Transfus 2103; 11: 491-499.

7 Rowe JA, Handel IG, Thera MA, Deans AM, Lyke KE, Koné A et al. Blood group $O$ protects against severe Plasmodium falciparum malaria through the mechanism of reduced rosetting. Proc Natl Acad Sci USA 2007; 104: 17471-17476.

8 Goel S, Palmkvist M, Moll K, Joannin N, Lara P, Akhouri RR et al. RIFINs are adhesins implicated in severe Plasmodium falciparum malaria. Nat Med 2015; 21: 314-317.

9 Huai G, Qi P, Yang H, Wang Y. Characteristics of $\alpha$-Gal epitope, anti-Gal antibody, $\alpha 1,3$ galactosyltransferase and its clinical exploitation (review). Int J Mol Med 2016; 37: 11-20.

10 Hamanova M, Chmelikova M, Nentwich I, Thon V, Lokaj J. Anti-Gal IgM IgA and IgG natural antibodies in childhood. Immunol Lett 2015; 164: 40-43.

11 Macher BA, Galili U. The Galalpha1,3Galbeta1,4GlcNAc-R (alpha-Gal) epitope: a carbohydrate of unique evolution and clinical relevance. Biochim Biophys Acta 2008; 1780: 75-88.

12 Rispens T, Derksen NI, Commins SP, Platts-Mills TA, Aalberse RC. IgE production to $\alpha$-gal is accompanied by elevated levels of specific IgG1 antibodies and low amounts of IgE to blood group B. PLOS ONE 2013; 8: e55566.

13 Muthana SM, Gildersleeve JC. Factors affecting anti-glycan IgG and IgM repertoires in human serum. Sci Rep 2016; 6: 19509.

14 Yilmaz B, Portugal S, Tran TM, Gozzelino R, Ramos S, Gomes J et al. Gut microbiota elicits a protective immune response against malaria transmission. Cell 2014; 159: 1277-1289.

15 Cabezas-Cruz A, Mateos-Hernández L, Pérez-Cruz M, Valdés JJ, Mera IG, Villar M et al. Regulation of the immune response to $\alpha$-Gal and vector-borne diseases. Trends Parasitol 2015; 31: 470-476.

16 Soares MP, Yilmaz B. Microbiota control of malaria transmission. Trends Parasitol 2016; 32: 120-130.

17 Chung $\mathrm{CH}$, Mirakhur B, Chan E, Le QT, Berlin J, Morse M et al. Cetuximabinduced anaphylaxis and IgE specific for galactose-alpha-1,3-galactose. N Engl J Med 2008; 358: 1109-1117.

18 Commins SP, James HR, Kelly LA, Pochan SL, Workman LJ, Perzanowski MS et al. The relevance of tick bites to the production of IgE antibodies to the mammalian oligosaccharide galactose- $\alpha-1,3$-galactose. J Allergy Clin Immunol 2011; 127: 1286-1293.

19 Commins SP, Platts-Mills TA. Tick bites and red meat allergy. Curr Opin Allergy Clin Immunol 2013; 13: 354-359.

20 Hay SI, Snow RW. The malaria Atlas project: developing global maps of malaria risk. PLoS Med 2006; 3: e473.

21 Bhatt S, Weiss DJ, Cameron E, Bisanzio D, Mappin B, Dalrymple U et al. The effect of malaria control on Plasmodium falciparum in Africa between 2000 and 2015. Nature 2015; 526: 207-211.

22 World Health Organization (WHO). World Malaria Report. WHO, 2015. Available at http://www.who.int/malaria/publications/world-malaria-report2015/wmr2015-profiles.pdf.

23 Quandl. Quandl Data Platform. Quandl, 2008; https://www.quandl.com/ collections/demography/tuberculosis-prevalence-rate-by-country.

24 Bhatt S, Gething PW, Brady OJ, Messina JP, Farlow AW, Moyes CL et al. The global distribution and burden of dengue. Nature 2013; 496: 504-507.

25 Duarte R, Afonso A, Ferreira C, Roque S, Vasconcelos O, Sarmento-Castro R et al. A case-control study on the diagnostic potential of multi-antigen serological tests for tuberculosis. Arch Clin Microbiol 2012; 3: 1.

26 Sagna AB, Sarr JB, Gaayeb L, Drame PM, Ndiath MO, Senghor S et al. gSG6-P1 salivary biomarker discriminates micro-geographical heterogeneity of human exposure to Anopheles bites in low and seasonal malaria areas. Parasit Vectors 2013; 6: 68 
27 Gaayeb L, Sarr JB, Ndiath MO, Hanon JB, Debrie AS, Seck M et al. Seroprevalence of pertussis in senegal: a prospective study. PLOS ONE 2012; 7: e48684.

28 Ndiath MO, Sarr JB, Gaayeb L, Mazenot C, Sougoufara S, Konate L et al. Low and seasonal malaria transmission in the middle Senegal River basin: identification and characteristics of Anopheles vectors. Parasit Vectors 2012; 5: 21.

29 Hansen C, Paintsil E. Infectious diseases of poverty in children: a tale of two worlds. Pediatr Clin North Am 2016; 63: 37-66.

30 World Health Organization (WHO). Tuberculosis (Fact sheet No 104), WHO, 2015. Avaialble at http://www.who.int/mediacentre/factsheets/fs104/en/.

31 Horstick O, Tozan Y, Wilder-Smith A. Reviewing dengue: still a neglected tropical disease? PLoS Neg/ Trop Dis 2015; 9: e0003632.

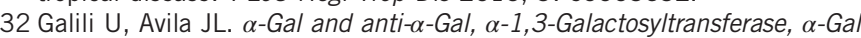
epitopes, and the natural anti-Gal antibody. Springer US Press: NY, USA, 1999.

33 Galili U, Buehler J, Shohet SB, Macher BA. The human natural anti-Gal IgG. III. The subtlety of immune tolerance in man as demonstrated by crossreactivity between natural anti-Gal and anti-B antibodies. J Exp Med 1987; 165: 693-704.

34 Galili U, Rachmilewitz EA, Peleg A, Flechner I. A unique natural human IgG antibody with anti-alpha-galactosyl specificity. J Exp Med 1984; 160: 1519-1531.

35 Galili U, Anaraki F, Thall A, Hill-Black C, Radic M. One percent of human circulating $B$ lymphocytes are capable of producing the natural anti-Gal antibody. Blood 1993; 82: 2485-2493.

36 McMorrow IM, Comrack CA, Nazarey PP, Sachs DH, DerSimonian H. Relationship between $\mathrm{ABO}$ blood group and levels of $\mathrm{Gal}$ alpha,
3Galactose-reactive human immunoglobulin G. Transplantation 1997; 64: 546-549.

37 Bernth-Jensen JM, Møller BK, Jensenius JC, Thiel S. Biological variation of anti- $\alpha \mathrm{Gal}$-antibodies studied by a novel Time-Resolved ImmunoFluorometric Assay. J Immunol Methods 2011; 373: 26-35.

38 Kristian SA, Hwang JH, Hall B, Leire E, lacomini J, Old R et al. Retargeting pre-existing human antibodies to a bacterial pathogen with an alpha-Gal conjugated aptamer. J Mol Med 2015; 93: 619-631.

39 Villarino NF, LeCleir GR, Denny JE, Dearth SP, Harding CL, Sloan SS et al. Composition of the gut microbiota modulates the severity of malaria. Proc Natl Acad Sci USA 2016; 113: 2235-2240.

40 Cabezas-Cruz A, Valdés JJ, de la Fuente J. Control of vector-borne infectious diseases by human immunity against $\alpha$-Gal. Expert Rev Vaccines 2016; 15: 953-955.

(c) (i) $(-)$ This work is licensed under a Creative Commons Attribution-NonCommercial-NoDerivs 4.0 International License. The images or other third party material in this article are included in the article's Creative Commons license, unless indicated otherwise in the credit line; if the material is not included under the Creative Commons license, users will need to obtain permission from the license holder to reproduce the material. To view a copy of this license, visit http://creativecommons.org/licenses/by-nc-nd/4.0/

Supplementary Information accompanies the paper on Experimental \& Molecular Medicine website (http://www.nature.com/emm) 